\title{
Behavioral and hormonal effects of hippocampal lesions on male and female rats*
}

\author{
RICHARD C. KEARLEY, CAROL VAN HARTESVELDT $\dagger$, and MICHAEL L. WOODRUFF \\ University of Florida, Gainesville, Florida 32611
}

\begin{abstract}
Male and female rats with hippocampal lesions and controls were compared with respect to activity, body weight, performance on a DRL schedule, and extinction. Normal females acquired the DRL schedule faster than normal males. For both sexes, hippocampal lesions resulted in poor DRL performance and more responses during extinction. Male rats with hippocampal lesions were further below their target deprived weight each day than their controls; the lightest animals had the worst DRL performance. Sex-lesion interactions were found for activity in the operant chamber during DRL performance and for DRL extinction: females with hippocampal lesions were more active and made more responses during extinction than males with hippocampal lesions. Corticosterone levels were manipulated prior to DRL sessions, and resting and stress levels of corticosterone were measured at the end of the experiment. While females had higher corticosterone levels than males, brain lesions did not affect corticosterone levels, nor did hormone manipulations affect DRL performance for either sex.
\end{abstract}

The behavior of male and female animals on many tasks differs, suggesting that those behaviors are at least in part mediated by hormones. The effects of brain lesions on the behavior of male and female animals may also differ. For example, lesions of the ventromedial hypothalamus result in a greater increase in food consumption in female than in male rats (Cox, Kakolewski, \& Valenstein, 1966), and female rats with septal lesions respond at higher rates on fixed-interval schedules than male rats with septal lesions (Kondo \& Lorens, 1971). These results suggest that at least some of the behavioral effects of brain damage are mediated by hormones. We chose to examine the hypothesis that some of the effects of lesions of the hippocampus are mediated by the pituitary-adrenal hormones and have studied the effects of hippocampal lesions on male and female rats. This approach was chosen because of the reported similarities between female animals and animals with hippocampal lesions with respect to both behavior and pituitary-adrenal activity.

On several tasks, female animals differ from males in the same direction that animals with hippocampal lesions differ from normals. Females have greater locomotor activity than males (Smith, 1972; Russell, 1971; Denenberg \& Morton, 1962; Thorne \& Linder, 1971; Valle, 1970), as rats with hippocampal lesions are more active than normals (Teitelbaum \& Milner, 1963; Douglas \& Isaacson, 1964; Strong \& Jackson, 1970). Like females (Smith, 1972), animals with hippocampal lesions made more errors in Hebb-Williams mazes

*This research was supported in part by NIMH Grant MH 22199-01 to $C$. Van Hartesveldt and by USPHS Training Grant MH 10320-09 to the Center for Neurobiological Sciences, University of Florida. The paper is based upon research conducted by the first author in partial fulfillment of the requirements for the degree of Master of Science at the University of Florida, Department of Psychology.

thequests for reprints should be sent to Carol Van Hartesveld t, Department of Psychology, University of Florida, Gainesville, Florida 32611.
(Kimble, 1963). Females (Cole \& Blasczyk, 1971) and males with hippocampal lesions (Schmaltz \& Isaacson, 1966; Van Hartesveldt, 1973) acquire a continuously reinforced operant response faster than normal males. Both female rats (Denti \& Epstein, 1972) and rats with hippocampal lesions (Kimble, 1963; Isaacson \& Wickelgren, 1962) are poor at passive avoidance. Finally, both female rats (Beatty et al, 1971) and male rats with hippocampal lesions (Olton \& Isaacson, 1968) acquire a two-way active avoidance task faster than normal males. Thus, many differences between behaviors of male and female animals are in the same direction as those between animals with hippocampal lesions and normals, although not as great in magnitude.

The similarities between the behaviors of female rats and rats with hippocampal lesions suggest the possibility of a common underlying mechanism. In this regard, it has been reported that female rats have higher levels of corticosterone than males (Kitay, 1961; Critchlow et al, 1963), and that animals with hippocampal lesions have higher levels of corticosterone than normals (Knigge, 1961; Fendler et al, 1961). Furthermore, the pituitary-adrenal hormones are known to influence many behaviors (Levine, 1968), and it has been suggested that both male-female differences (Beatty et al, 1971) and differences between animals with hippocampal lesions and normals (Antelman \& Brown, 1972; Pagano \& Lovely, 1972) may be due to pituitary-adrenal differences in these animals. Therefore, if the effects of hippocampal lesions are even partially mediated by changes in the pituitary-adrenal system, then the resulting behavioral changes should be of different magnitude in males and females. In addition, since corticosterone levels fluctuate with the estrous cycle in females (Critchlow et al, 1963), behaviors mediated by corticosterone should also show cyclical changes in females. To explore these ideas, we tested male and female animals with hippocampal lesions on 
behaviors known to vary with sex or hippocampal lesion: locomotor activity, maintenance of body weight, performance on a DRL-20 schedule, and extinction. The effects of pituitary-adrenal hormone manipulations on DRL performance were also tested. At the end of the experiment, resting and stress levels of plasma corticosterone were measured in all animals.

\section{METHOD}

\section{Subjects}

This study was conducted with 42 Long-Evans hooded rats, 21 males and 21 females, obtained from Blue Spruce Breeding Farms. The males weighed $350-450 \mathrm{~g}$ and the females weighed $250-300 \mathrm{~g}$ after surgery. The animals were individually caged, with the males and females in the same cage rack. A normal 12-h light-dark cycle was maintained.

\section{Surgery}

The animals of each sex were divided in to three groups. One group received bilateral aspirative lesions of the hippocampus. The procedure for this surgical technique has been described previously (Isaacson, Douglas, \& Moore, 1961; Kimble, 1963). Another group of animals received bilateral aspirative lesions of the neocortex overlying the dorsal hippocampus. The third group of animals served as an unoperated control group.

\section{Apparatus}

The main apparatus used in this study was a set of four Lehigh Valley rodent test cages (Model 143-28), equipped to dispense 45-mg food pellets, mounted in Lehigh Valley small Universal isolation chambers (Model 132-02). These cages were controlled by standard relay programming equipment located in the adjoining room. The cages were slightly modified by the addition of a touch-sensitive circuit connected to the grid floor in such a way that it was possible to record how many times the animal moved from the front of the cage to the rear.

The other apparatus used was an open-field activity chamber, constructed of plywood painted dull gray, $1 \mathrm{~m}$ square and $46 \mathrm{~cm}$ deep. The top was open, and the floor was illuminated by a $22-\mathrm{W}$ circular fluorescent light mounted $1 \mathrm{~m}$ above it. The floor was covered with heavy brown paper divided into 16 equal squares. A different paper floor was used for each sex.

\section{Procedure}

Preoperative Training. The animals were food deprived until they reached $85 \%$ of their normal free-feeding weights. They were then given 7 days of 30 -min barpress training sessions. During this and all other phases of the experiment, male animals were run in two of the operant chambers and females were run in the other two, in order to eliminate distraction due to odor left by animals of the other sex. At the end of 7 days, all the animals had learned to barpress 100 times or more in each $30-\mathrm{min}$ session and they were started on the DRL-20 schedule. The animals were run daily for $30 \mathrm{~min}$ on this schedule for the next 50 consecutive days. During this time, vaginal smears were taken from the females, by the method of Snell (1941), after they were removed from the operant chamber each day. These smears were stained with hematoxylin so that the cell types might be distinguished.

Preoperative Open Field. At the end of the 50 days of DRL training, the activity levels of the animals, which were still food deprived, were measured in the open field on 3 successive days. Both the number of squares entered by more than half of the rat's body and the number of times the rat reared onto its hindlegs were recorded. The test session was $10 \mathrm{~min}$ long for each animal. After 3 days of measuring the activity level of the animals while they were food deprived, the were allowed free access to Purina Lab Chow for 5 days. They sre then tested for 3 more days in the open field, as before.
Postoperative Retraining. Two days after open-field testing, the animals of each sex were randomly divided into three groups and surgery was performed. The animals were given a 2 -week recovery period, food deprived back down to $85 \%$ of their ad lib body weights, and returned to the DRL-20 schedule, a total of 20 days postoperatively. The animals were run daily for $30 \mathrm{~min}$ without further manipulations for the next 50 consecutive days. During the period from Postoperative Day 25 to Postoperative Day 40, the locomotor activity of the animals during the operant session was recorded by the touch-sensitive circuits in the floors of the operant chambers.

Hormone Manipulations. On Postoperative Day 51, a series of hormone manipulations was begun with the injection of the vehicle, $0.05 \mathrm{ml} 100 \%$ alcohol, subcutaneously $1 \mathrm{~h}$ before the start of the DRL-20 test session. The first horm one given was corticosterone (Sigma Chemical Co.). An ascending series of doses was given: on Day 54, $0.1 \mathrm{mg}$; on Day $57,0.2 \mathrm{mg}$; on Day 60, $0.4 \mathrm{mg}$; on Day 63, 0.8 mg; on Day 66, $1.6 \mathrm{mg}$; and on Day 69, $3.2 \mathrm{mg}$ corticosterone. On Days 72, 73, and 74, $3.2 \mathrm{mg}$ corticosterone were given. On Day 79, all animals were given 10 I.U. of adrenocor ticotropic hormone (ACTH) in $0.1 \mathrm{ml}$ of $9 \%$ saline subcutaneously $1 \mathrm{~h}$ before the test session to stimulate the release of endogenous corticosterone.

Extinction and Postoperative Activity Measures. Three days after the final hormone injection, on Postoperative Day 82, the animals were placed on an extinction schedule. They were run on the extinction schedule for $30 \mathrm{~min}$ daily for the next 15 consecutive days. Following 15 days of extinction, the open-field activity of the food-deprived animals was again recorded as described above. On Days 101 and 102, the animals were returned to the operant chambers, but the operant bars were retracted; the activity of the animals in the chambers was recorded by the touch circuit in the grid floor. Following this test, the animals were returned to ad lib feeding of Purina Lab Chow. On Postoperative Days 106-109, the open-field activity of the animals, which were now satiated, was again measured as described above. On Postoperative Days 110 and 111 , the satiated animals were again returned to the operant chambers, where their locomotor activity with the manipulanda retracted was recorded. During this entire period, starting on Postoperative Day 82 , in which the animals were food deprived but were not receiving any food during the testing sessions, the amount of food required each day for each animal to maintain a stable weight was recorded. The weight of the animal before feeding was also recorded.

Plasma Corticosterone Measurement. After all behavioral tests were completed, blood samples were taken from the animals by direct heart puncture with a 23-ga needle under ether anesthesia. The first sample, or the resting level, was taken $1 \mathrm{~h}$ before the lights came on in the colony room. Six animals were sampled per day, so the time of day at which the samples were taken was relatively constant for all animals. The first sample was obtained within 2 min after the animal was lifted from his home cage to avoid stress responses to handling. A second sample, or stress level, was taken $15 \mathrm{~min}$ after the first sample, when the animals were responding to the ether stress of the first sample. The blood plasma was fluorometrically assayed for corticosterone by a modification of the method of Silber, Busch, and Oslapas (1958).

\section{Histology}

Following all testing, the animals were sacrificed with Nembutal and perfused with saline, followed by $10 \%$ Formalin. The brains were removed and embedded in celloidin. Sections were cut at 30 microns, and every fifth section was saved and stained with thionin.

\section{RESULTS}

Preoperative DRL Performance

Preoperative response rates for males and females are 


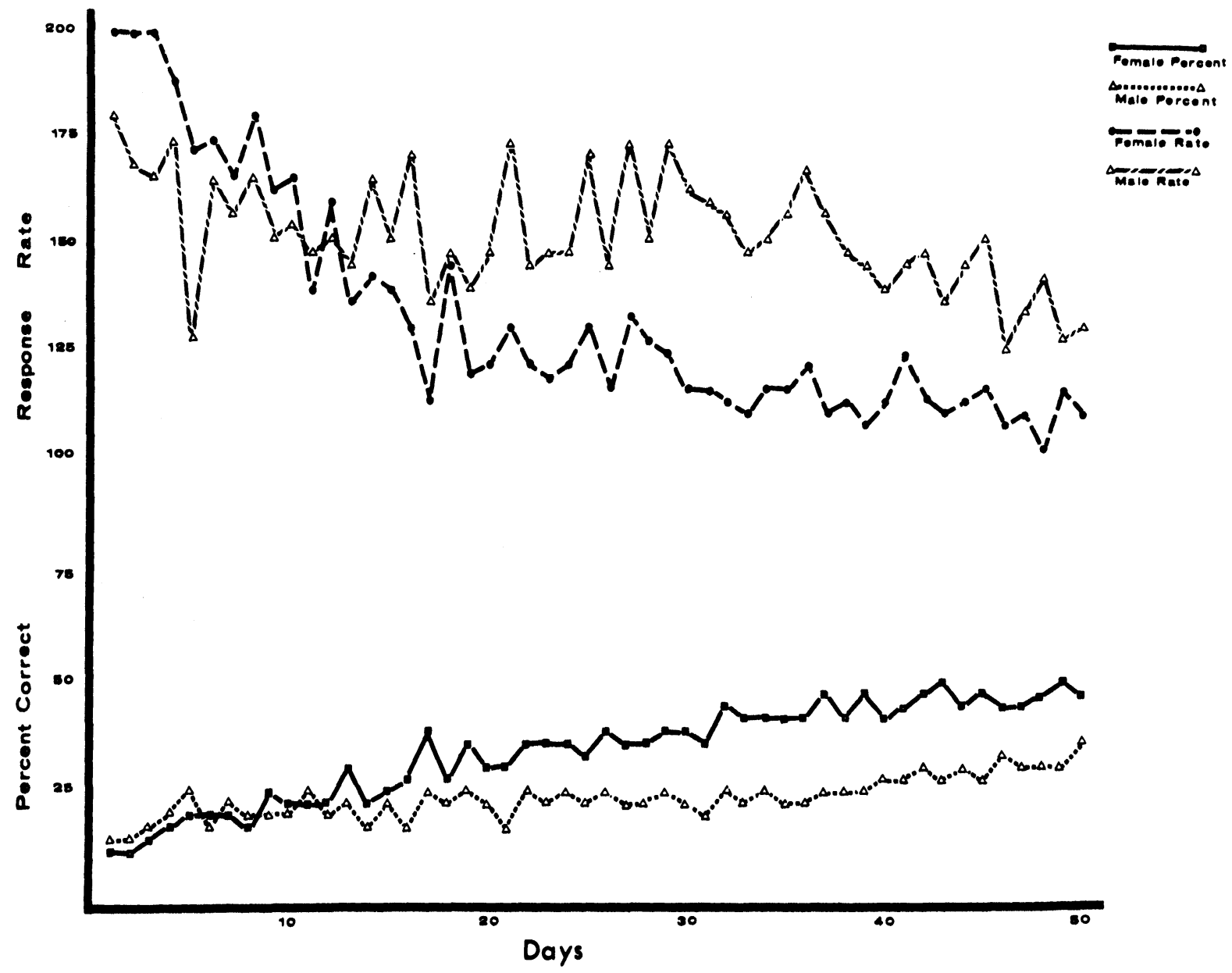

Fig. 1. Mean response rates and efficiency scores on the DRL schedule before surgery for normal males and females.

shown in Fig. 1. Response rates decreased until approximately Day 40 , and stabilized thereafter, as indicated by the results of analysis of variance (ANOVA): a significant days effect $(\mathrm{p}<.01)$ was found for Days 1-20 and Days 21-39, but not for Days 40-50. No differences between males and females were found over the first 20 days, but response rates for females were significantly lower than those for males for Days 21-39 $(\mathrm{p}<.01)$ and Days 40-50 $(\mathrm{p}<.05)$.

Mean efficiency scores (reinforced responses/total responses) for males and females are also shown in Fig. 1. Efficiency scores increased over the first 20 days (significant days effect, $p<.01$ ). During Days 21-39, the females began to achieve higher efficiency scores than the males (significant interaction, $\mathrm{p}<.05$ ), and stabilized at a higher level during Days 40-50 (significant sex effect, $p<.05$ ).

\section{Estrous Cycle Effects}

During this same 50 days of preoperative DRL training, the effects of estrous cycle changes on the operant performance of the female rats were evaluated by visual inspection of computer-produced graphs of the daily response rates of the animals. While several of the animals' vaginal smears did not indicate that they were cycling on a normal 4- or 5-day cycle, all animals showed at least occasional days when they were in estrus (vaginal smear revealed only cornified cells). The response rates on estrous days were not consistently higher or lower than on nonestrous days, and none of the response-rate graphs revealed any cyclicity in performance.

\section{Open Field}

Open-field activity tests after the completion of the first 50 days of DRL training revealed no significant sex differences for normal rats in either the number of squares entered or the number of times the animals reared up. On both measures, both food deprived and satiated, the mean score for the females was slightly, but not significantly, higher than that of the males. All scores were lower when the animals were satiated than when they were food deprived, but this difference was not statistically significant.

\section{Postoperative DRL Performance}

Response rates for the first 40 days of DRL retraining 


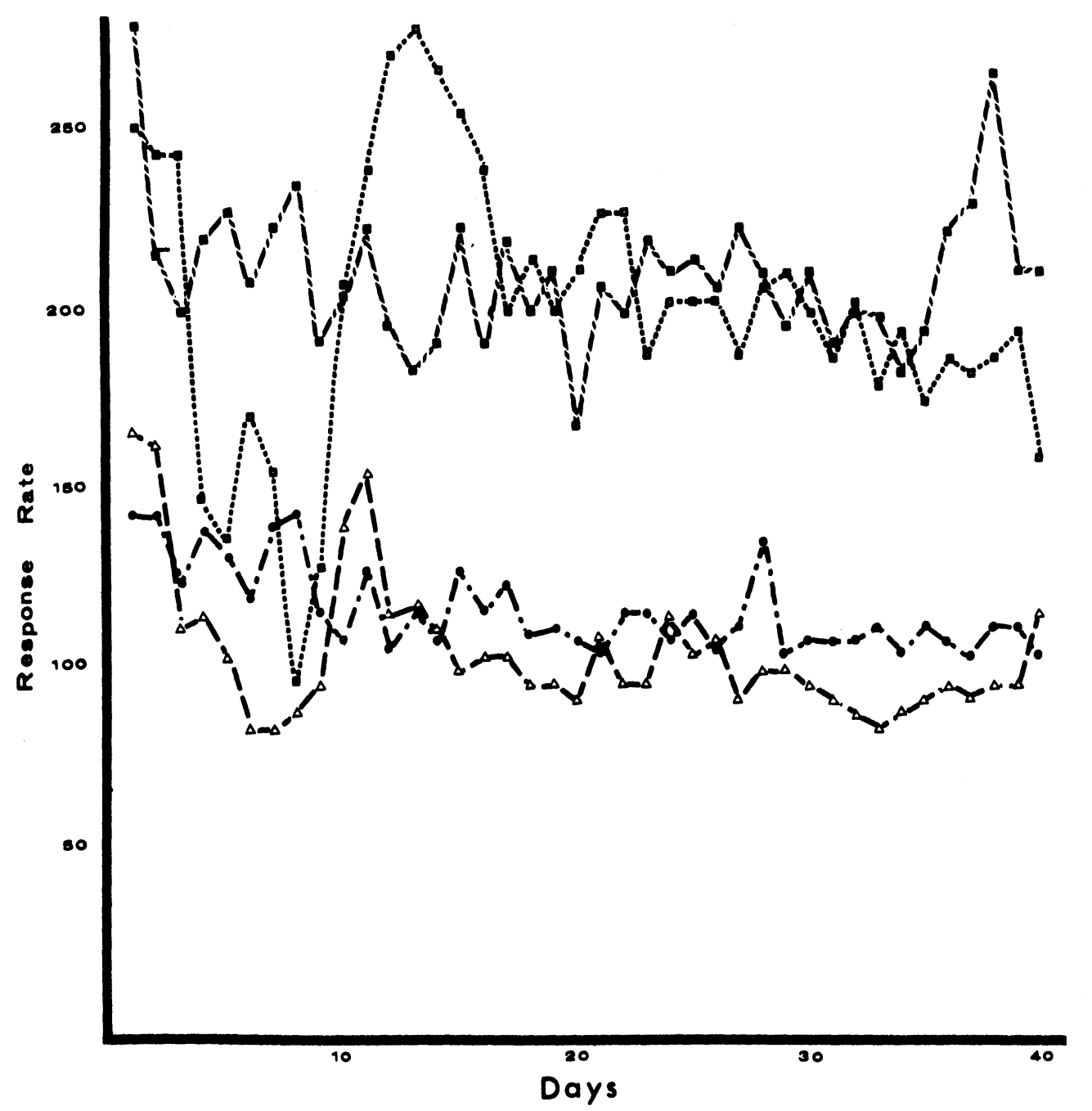

Fig. 2. Mean response rates on the DRL schedule for the first $\mathbf{4 0}$ days after surgery.

after surgery are shown in Fig. 2. Response rates for animals with cortical lesions are not shown, since they are so similar to response rates of the appropriate normal groups. ANOVA revealed no sex differences within lesion groups. ANOVA for males revealed a significant $(p<.01)$ lesion effect; Newman-Keuls tests showed that male animals with hippocampal lesions had significantly $(p<.01)$ higher response rates than either normal males or males with cortical lesions; the latter two groups did not significantly differ from each other. ANOVA for females revealed significant lesion $(p<.01)$, days $(p<.01)$, and interaction $(p<.05)$ effects. Newman-Keuls tests showed that females with hippocampal lesions had significantly $(\mathrm{p}<.01)$ higher response rates than either normal females or females with cortical lesions on all days except Days 4-9 and 40. Inspection of Fig. 2 reveals that the decrease in response rate for females with hippocampal lesions, but not for other females, on Days 4-9 probably accounts for the significant days and interaction effer ${ }^{2} s$. No significant differences were found between response rates for normal females and females with cortical lesions.

Mean efficiency scores for the first 40 days of retraining are presented in Fig. 3; again, data for animals with cortical lesions are not shown. ANOVA revealed no sex differences within lesion groups. ANOVAs for all animals and for both males and females revealed significant $(\mathrm{p}<.01)$ lesion, days, and interaction effects. Subsequent one-way ANOVAs and Newman-Keuls tests showed that there were no significant differences between the lesion groups on the 2 nd, 4 th, and 9 th days of postoperative training thereafter, and normal animals and animals with cortical lesions had significantly higher efficiency scores than animals with hippocampal lesions.

\section{Activity in Operant Chambers}

During the DRL retraining period, activity was monitored in the operant chambers on Days 25-40. A summary of the data for this portion of the experiment is presented in Table 1. ANOVA was carried out on 


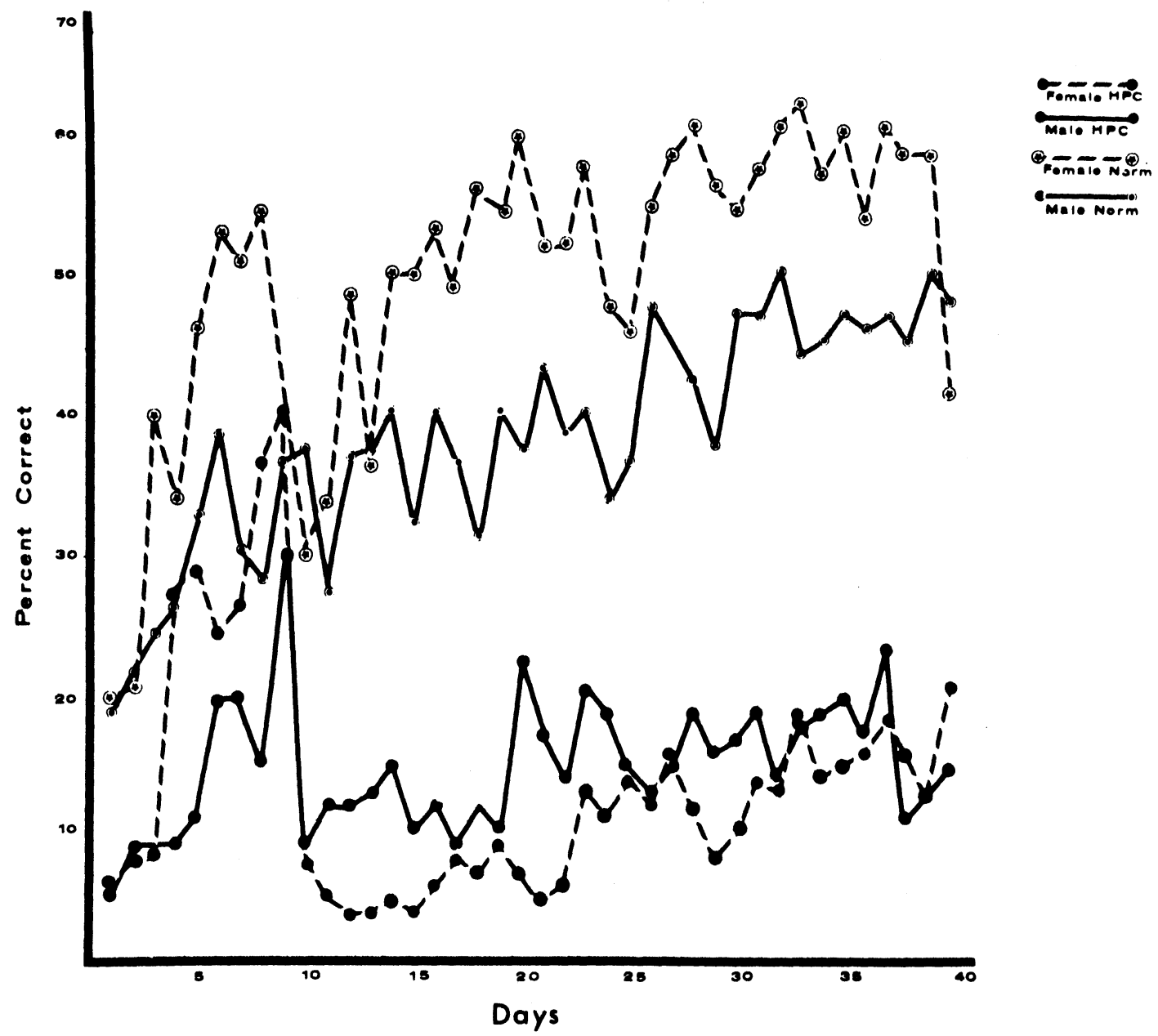

Fig. 3. Mean efficiency scores on the DRL schedule for the first 40 days after surgery.

these activity counts. Within-sex analysis revealed no significant lesion or days effects for the male animals. For the females, however, significant $(p<.01)$ lesion, days, and interaction effects were seen. Newman-Keuls tests revealed that on all days females with hippocampal lesions were significantly $(\mathrm{p}<.01)$ more active than normal females. On all days except Days 28 and 36, they

Table 1

Mean Activity Counts Recorded from the Operant Chambers

\begin{tabular}{lcccc}
\hline & DRL & $\begin{array}{c}\text { Extinc- } \\
\text { tion } \\
\text { Days } \\
\text { Days } \\
25-40\end{array}$ & $\begin{array}{c}\text { Bars Retracted } \\
\text { Deprived } \\
\text { Days } \\
101-102\end{array}$ & $\begin{array}{c}\text { Satiated } \\
\text { Days } \\
110-111\end{array}$ \\
\hline $\begin{array}{l}\text { Male-Hippo- } \\
\text { campal Lesion }\end{array}$ & 192.0 & 211.4 & 242.8 & 167.9 \\
$\begin{array}{l}\text { Male-Cortical } \\
\text { Lesion }\end{array}$ & 109.0 & 101.0 & 116.7 & 153.9 \\
$\begin{array}{l}\text { Male-Normal } \\
\text { Female-Hippo- }\end{array}$ & 165.7 & 113.3 & 82.0 & 93.9 \\
$\begin{array}{l}\text { campal Lesion } \\
\text { Female-Corti- }\end{array}$ & 468.3 & 280.7 & 259.5 & 191.1 \\
$\begin{array}{l}\text { cal Lesion } \\
\text { Female-Normal }\end{array}$ & 136.5 & 128.4 & 84.8 & 107.9 \\
\hline
\end{tabular}

were also more active $(p<.01)$ than females with cortical lesions.

Comparison within lesion groups revealed a significant $(p<.05)$ sex effect in the hippocampal group, but also a significant $(p<.01)$ days effect and interaction. Subsequent one-way ANOVA tests revealed that females with hippocampal lesions were more active than males with hippocampal lesions on all days. Examination of the data revealed that the interaction effect was due to a steady increase in the activity of the female animals, while the males showed no change over days. Males with cortical lesions did not differ from females with cortical lesions. In the normal animals, a significant $(\mathrm{p}<.05) \mathrm{F}$ value was obtained for the sex effect, but a significant interaction $(p<.05)$ was also obtained. Subsequent one-way ANOVA tests revealed that the male animals were more active than females on all days measured with the exception of three. Neither normal group showed any trend over days.

Activity counts were also recorded during extinction and later with the operant levers retracted to investigate the effect of the schedule on this activity in the operant chamber. While a sex difference was seen in animals with 
Table 2

Mean Weights and Weight Changes During the Experiment

\begin{tabular}{|c|c|c|c|c|c|c|}
\hline & $\begin{array}{c}\text { Preoperative } \\
\text { Weight }\end{array}$ & $\begin{array}{c}\text { Postoperative } \\
\text { Weight }\end{array}$ & $\begin{array}{c}\text { Weight } \\
\text { Gain }\end{array}$ & $\begin{array}{c}\text { Postoperative } \\
85 \% \text { Weight }\end{array}$ & $\begin{array}{c}\text { Postoperative } \\
\text { Postsession } \\
\text { Weight }\end{array}$ & $\begin{array}{c}\text { Weight } \\
\text { Difference }\end{array}$ \\
\hline Male-Hippocampal Lesion & 353.4 & 371.1 & 17.7 & $315.4^{\circ}$ & 298.2 & 17.2 \\
\hline Male-Cortical Lesion & 363.8 & 404.6 & 40.8 & 343.9 & 330.7 & 13.2 \\
\hline Male-Normal & 367.5 & 410.7 & 43.2 & 349.1 & 335.6 & 13.5 \\
\hline Female-Hippocampal Lesion & 270.7 & 285.9 & 15.2 & 243.0 & 232.5 & 10.5 \\
\hline Female-Cortical Lesion & 270.7 & 279.0 & 8.3 & 237.2 & 229.2 & 8.0 \\
\hline Female-Normal & 259.7 & 272.3 & 12.6 & 231.2 & 222.8 & 8.4 \\
\hline
\end{tabular}

hippocampal lesions and in normal animals during the DRL-20 condition, no sex differences were seen during extinction or with the levers retracted in any of the three groups. During extinction, females with hippocampal lesions were found by ANOVA and subsequent Duncan's new multiple range tests to have significantly higher $(p<.05)$ activity counts than normal animals and animals with cortical lesions of either sex. A significant $(p<.01)$ days effect was found during extinction, but examination of the data revealed a U-shaped curve rather than a steady upward or downward trend. No significant differences between activity on the last day of DRL and the first or last day of extinction were revealed by $t$ tests.

Activity with bars retracted while the animals were still deprived did not differ much from the activity during extinction. Mean activity counts under the different conditions are shown in Table 1. Female animals with hippocampal lesions were still more active than female corticals and male normals. The activity of normal males and females with cortical lesions appeared to have dropped more than that of other groups, but these differences were not significant when tested with $t$ tests. When the animals were returned to free feeding, group differences disappeared. As may be seen in Table 1, this change appeared to be due to a drop in the activity of animals with hippocampal lesions, but again this drop from the deprived activity level was not significant for either sex. The activity of normal animals and animals with cortical lesions rose slightly following satiation, but the change was smaller than that seen in the animals with hippocampal lesions.

\section{Body Weight}

The body weight of each animal was recorded on the day before surgery and 2 weeks later. The data are presented in Table 2. No significant differences among lesion groups were found in the males or females. However, for the males with hippocampal lesions, the weight change after surgery was highly variable, ranging from a weight loss of $24 \mathrm{~g}$ to a weight gain of $49 \mathrm{~g}$. The weight changes of these animals were correlated with later performance on the DRL-20 schedule (Days 30-40); animals with the greatest weight increase earned more reinforcements ( $\mathrm{rho}=.750, \mathrm{p}<.05$ ). There were no significant correlations betwer 1 weight change and any DRL performance measure in any other group.

The body weight of each animal was also recorded on each day of the experiment after the operant session. Analysis of variance done on the scores during extinction and deprived activity measuring revealed a significant lesion effect $(\mathrm{p}<.05)$ and a significant days effect $(p<.01)$ only for the male animals. Newman-Keuls tests showed that male animals with hippocampal lesions were further below their 85\% weights than male animals with cortical lesions. These data are also shown in Table 2. Furthermore, the average difference from $85 \%$ weight in this portion of the experiment also correlated significantly with performance on the DRL-20 schedule (Days 30-40) for males with hippocampal lesions: the greater the difference from the $85 \%$ weight, the fewer the reinforcements the animal received (rho $=-.785$, $\mathrm{p}<.05)$. Again, there were no significant correlations between weight change and any DRL performance measure in any other group.

\section{Hormone Injections}

No significant changes in performance on the DRL task were observed following injections of either corticosterone or ACTH.

\section{Extinction}

The results of extinction following DRL experience are shown in Fig. 4. Data for male and female rats with cortical lesions are not shown because they are so similar to data for normal males and females. Because of the great variance in the scores of male rats with hippocampal lesions, median scores are plotted in the figure and nonparametric statistics were used.

The differences in response rate among groups were compared for each day of extinction using the Mann-Whitney U test. Although median scores for normal females were lower than those for normal males, the difference was statistically significant $(p<.05)$ only on Days 9,12 , and 14. No significant differences were found among males and females with cortical lesions. Females with hippocampal lesions had higher median scores than males with hippocampal lesions, which were statistically significant $(\mathrm{p}<.05)$ on Days $7,10,11,12$, and 14. Comparisons within sex revealed that males with hippocampal lesions had significantly higher response 
rates than normal males only on the first 3 days of extinction $(\mathrm{p}<.05)$ and significantly higher response rates than males with cortical lesions on Days 4,9 , and $10(\mathrm{p}<.05)$. Females with hippocampal lesions had significantly $(p<.01)$ higher scores than normal females on all days except Day 5 , and significantly $(p<.01)$ higher scores than females with cortical lesions on all days.

Since both male and female animals with hippocampal lesions had higher response rates on the DRL schedule than did controls, they began extinction from a different baseline than controls. To compare the decrease of response rates among groups, regression lines were fitted to the extinction curves over the first 8 days of extinction (Steel \& Torrie, 1960); scores for only the first 8 days were used, since normal animals appeared to have reached an asymptotic level at this time. The slopes of the curves were compared using $t$ tests (Steel \& Torrie, 1960). Only one pairwise comparison reached statistical significance: the slope for males with hippocampal lesions $(-15.4)$ was greater $(p<.05)$ than the slope for females with cortical lesions $(-8.0)$.

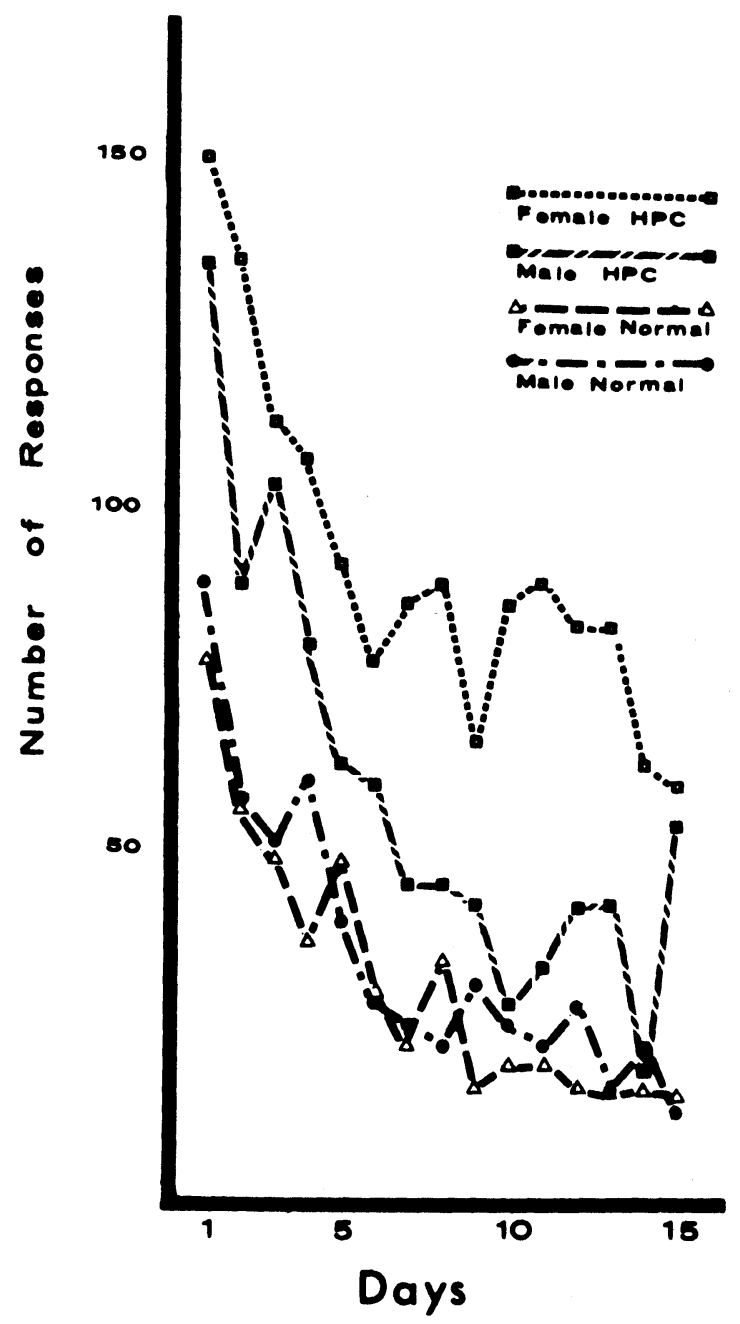

Fig. 4. Mean responses during ex tinction.
Table 3

Mean Plasma Levels of Corticosterone $(\mu \mathrm{g} / 100 \mathrm{ml})$ at the Conclusion of the Study

\begin{tabular}{|c|c|c|c|c|c|}
\hline \multicolumn{2}{|c|}{$\begin{array}{l}\text { Hippocampal } \\
\text { Lesion }\end{array}$} & \multicolumn{2}{|c|}{ Cortical Lesion } & \multicolumn{2}{|c|}{ Normal } \\
\hline Male & Female & Male & Female & Male & Female \\
\hline 11.9 & 27.2 & $\begin{array}{l}\text { Res } \\
16.3\end{array}$ & $\begin{array}{l}\text { g Mean } \\
27.8\end{array}$ & 15.4 & 28.6 \\
\hline 43.3 & 91.3 & $\begin{array}{l}\text { Stre } \\
38.2\end{array}$ & $\begin{array}{l}\text { Mean } \\
99.5\end{array}$ & 48.3 & 106.0 \\
\hline 31.1 & 70.3 & $\begin{array}{l}\text { Cha } \\
22.4\end{array}$ & $\begin{array}{c}\text { e Mean } \\
71.8\end{array}$ & 31.0 & 77.4 \\
\hline
\end{tabular}

\section{Postoperative Open Field}

Postoperatively, none of the open-field measures, which were taken for 3 days after the animals had completed 15 days of extinction and again for 3 days after the animals were no longer food deprived, revealed any sex differences or any lesion effects.

\section{Corticosterone Levels}

The data on plasma corticosterone levels of these animals were presented in Table 3. ANOVA showed that there were no significant differences due to lesions in either sex in the resting or stressed levels or the change due to stress. Since the lesion groups did not significantly differ, they were combined for each sex and another ANOVA was run on the combined groups. The levels for females were found to be significantly higher $(p<.01)$ under both resting and ether stress conditions. The percentage increase after stress for the females was also significantly $(p<.05)$ greater than for the males.

\section{Histology}

Histological examination of the brains revealed that the lesions were of comparable size in the two sexes. Cortical control lesions generally caused more extensive cortical damage than that incurred in the process of removing the hippocampus. Cortical lesions severed the corpus callosum, as did the hippocampal lesions. As may be seen in Fig. 5, hippocampal lesions were nearly total with some sparing of the ventral tip of the hippocampus. Slight thalamic damage was seen in some of the animals with hippocampal lesions, but this damage was not considered extensive enough to remove these animals from the study. Gliosis was observed in the medial and lateral geniculate bodies in most of the animals with brain lesions.

\section{DISCUSSION}

The present study was undertaken to evaluate the degree to which the behavioral effects of hippocampal lesions and the sex of the animal interact, and thus to evaluate the hypothesis that behavioral effects of hippocampal lesions may in part be mediated by hormones. As expected from previous reports (Kitay, 

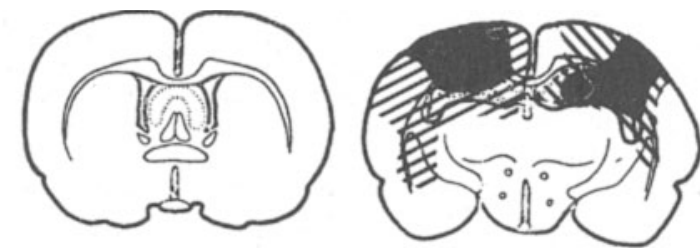

Fig. 5. Minimal and maximal extent of hippocampal lesions.

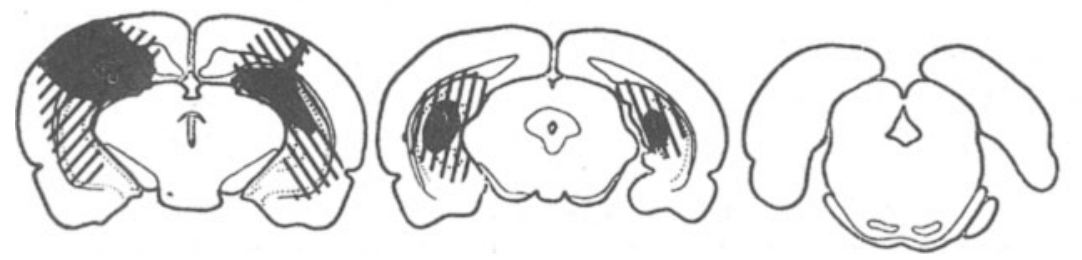

1961; Critchlow et al, 1963), female rats in the present study were found to have higher resting and stress levels of plasma corticosterone than males. Several behavioral differences between the sexes were also found. During initial DRL training, female rats performed better than male rats: female rats had a lower response rate and a higher percentage of correct responses. During postoperative DRL retraining, female rats had an early decrease in response rate, while males did not. As postoperative training progressed, the same sex differences were seen in the normal animals as during initial DRL training: female rats performed better. These findings are congruent with Levine's (1968) contention that high levels of plasma corticosterone improve DRL performance. However, neither corticosterone nor ACTH administration had a significant effect on the DRL performance of animals of either sex. In addition, in the present study no relationships were found between phases of the estrous cycle, during which levels of plasma corticosterone are known to vary (Critchlow et al, 1963), and performance on the DRL task. These findings weaken the hypothesis that there is a direct relationship between levels of plasma corticosterone and DRL performance. Performance on other schedules may be more sensitive to hormone changes; for example, responding on a fixed ratio schedule varies during estrus (Harris \& Heistad, 1970).

Extinction is a behavioral change known to be influenced by hormones of the pituitary-adrenocortical system. It has been reported that adrenocorticotropic hormone (ACTH) prolongs extinction both from avoidance tasks (Weiss et al, 1970) and from appetitive tasks (Guth, Levine, \& Seward, 1971). Beatty et al (1971) found that female rats were more resistant than males to extinction from avoidance tasks, and suggested that this difference was due to the fact that females have higher levels of ACTH than males. However, in the present study, normal females responded at a slightly lower rate than normal males during extinction, which suggests that other horm ones or neural mechanisms must be involved in the sex differences ir DRL extinction.
This behavior showed a clear sex-lesion interaction. Females with hippocampal lesions had higher response rates than males with hippocampal lesions, and were significantly different from female control groups throughout extinction; males with hippocampal lesions responded at a significantly higher rate than their controls for only a few sessions. Thus, the effect of the hippocampal lesion on response rate during extinction was greater for females than for males. Since hippocampal lesions did not affect corticosterone levels in males or females, the role of the pituitary-adrenocortical hormones in this sex-lesion interaction is not clear.

One premise of the present study was that hippocampal ablation would increase levels of plasma corticosterone. However, hippocampal ablation had no effect on resting or stress levels of plasma corticosterone. Our finding is at odds with the generally accepted interpretation that the hippocampus is a tonic inhibitor of hypothalamic-pituitary-adrenocortical activity, but this interpretation is predominantly based on the results of studies in which low-frequency stimulation of the hippocampus prevents the rise in plasma corticosterone normally elicited by a stressful stimulus (e.g., Mason, 1958; Endroczi et al, 1959; Kawakami et al, 1968). In two studies, it has been reported that hippocampal lesions in rat (Knigge, 1961) and cat (Fendler et al, 1961) resulted in elevated basal levels of plasma corticosteroids. The procedure used by Fendler et al makes it unlikely that basal levels were being measured; in Knigge's study, relatively small electrolytic lesions were made. In the only other published experiment dealing with the effects of large aspirative lesions of the hippocampus on plasma corticosterone (Coover et al, 1971), no differences in resting or stress levels of this hormone were found as a consequence of the lesion. It is possible that the hippocampus is regionally organized with respect to hormone control, and that damaging small regions will produce different effects than near-total damage. The present results do not rule out the possibility that animals with hippocampal lesions 
have higher stress levels of ACTH than normals, since plasma corticosteroid level accurately reflects ACTH levels only at submaximal adrenal cortical response. Furthermore, it is possible that plasma corticosterone levels might differ among lesion groups as a function of the stress of the DRL schedule. Research on this problem is in progress.

The results of DRL retraining after hippocampal ablation were similar to those previously reported (Schmaltz \& Isaacson, 1966). After hippocampal ablation, animals of both sexes had higher response rates and lower percentages of reinforced responses than control groups. During extinction, animals with hippocampal lesions made more responses than did controls. These results are consistent with many reports that hippocampal ablation results in greater resistance to extinction (see Kimble, 1968). However, if the present extinction results are viewed in terms of the rate of decrease from a previous level of responding, then we found no deficits as a consequence of hippocampal ablation, and hence no deficit in ability to generate response inhibition. Thus, very different conclusions about the internal processes altered by hippocampal ablation can be drawn, depending upon whether one considers the extinction data with reference to the rate or strength of the response which was extinguished.

Some unexpected results were found in the activity measures used in this study. Open-field activity measures have frequently been reported to increase after hippocampal ablation (e.g., Douglas \& Isaacson, 1964; Strong \& Jackson, 1970), but did not do so in the present study. In previous studies, the animals have been tested within about 1 month after surgery, but in the present study, the animals were not tested on this measure until about 120 days after surgery. The apparent recovery of function in the present study may have been simply a function of time, or it may have been influenced by the extensive handling and deprivation which took place during this time.

Consistent with previous reports (Kim, 1960; Kaplan, 1968; Clark, 1970), no activity differences were found in the present study between animals with hippocampal ablation and controls in small (operant) chambers when the animals were satiated. However, the activity of animals with hippocampal lesions increased more than that of the controls during deprivation, although only the scores of the females with hippocampal lesions differed significantly from their controls. Since interactions between deprivation and hippocampal ablation have not previously been reported with respect to activity in the open field, it is possible that this effect occurs only in small chambers. Activity in the operant chambers during DRL sessions was quite different from that recorded with levers retracted. The activity of the females with hippocampal lesions was significantly higher than that of male animals with hippocampal lesions, while the activity of normal females was lower than that of normal males, indicating a strong interaction between lesion and sex.

Activity in the chamber during DRL performance may be schedule-induced behavior (Falk, 1971). It is of particular interest that females with hippocampal lesions had both high response rates and high activity levels, in spite of the fact that these would seem to be conflicting responses. While males with hippocampal lesions did not have significantly higher activity scores than their controls, they may have engaged in different schedule-induced behavior, as we observed that the Sani-Cel under the grid floor of the chambers in which the male animals were tested was chewed into ex tremely small pieces. Unfortunately, this observation was not made until the end of the experiment, so it was not possible to determine whether all males were chewing or whether there were lesion group differences. Our findings suggest that the particular schedule-induced behavior exhibited may be a function of sex of the animal.

Hippocampal ablation has had variable effects on food intake and body weight in previous studies. Hippocampal ablation has resulted in a significant increase in food intake in some studies (Kimble \& Coover, 1966; Wishart, Brohman, \& Mogenson, 1969) but not in others (Boitano et al, 1968; Gotsick, 1969; Jarrard, 1965). Hippocampal ablation has been reported to produce a significant decrease in body weight (Murphy, Wideman, \& Brown, 1973) or no change in body weight (Kimble \& Coover, 1966; Boitano et al, 1968). In the present study, animals with hippocampal lesions were lighter, but not significantly so, than their controls when weighed 2 weeks after surgery while on ad lib diet. When these animals were food deprived to $85 \%$ of their postoperative body weights, they were significantly further below their target weights at feeding time than their controls. Whether the differences in the body weights during deprivation was a consequence of food spillage or a change in metabolism, the result of this method of deprivation is that the male animal with a hippocampal lesion is tested at a weight further below both his preoperative ad lib weight and his postoperative target deprivation weight than his controls. This difference in deprivation level might contribute to differences in performance on appetitive tasks. In the present study, the further the departure from either of these reference weights, the fewer the reinforcements received on the DRL schedule by males with hippocampal lesions. These correlations do not necessarily imply causation of the latter by the former since DRL performance is relatively insensitive to changes in deprivation level (see Kramer \& Rilling, 1970); both weight changes and behavioral changes might reflect an interaction of the hippocampus with hypothalamic mechanisms.

In summary, female rats had higher resting and stress levels of corticosterone than did males. Female and male rats also differed with respect to acquisition of the DRL schedule, reacquisition of the DRL schedule after 
surgery, and activity in the operant conditioning chamber during DRL performance. However, no relationships between estrous cycle and DRL performance were found, and neither ACTH nor corticosterone administration significantly affected DRL performance. Furthermore, in the present experiment, hippocampal lesions did not significantly alter resting or stress levels of corticosterone, but did result in a deficit in DRL performance, a greater number of responses during extinccion, and greater activity in some conditions. Thus, the hypothesis that a common mechanism underlies both sex differences and effects of hippocampal lesions was not supported. For only two behaviors was there a substantial sex-lesion interaction: activity in the operant conditioning chamber during DRL performance, and response rate during extinction.

\section{REFERENCES}

Antelman, S. M., \& Brown, T. S. Hippocampal lesions and shuttlebox avoidance behavior: A fear hypothesis. Physiology \& Behavior, 1972, 9, 15-20.

Beatty, W. W., Beatty, P. A., \& Bowman, R. E. A sex difference in the extinction of avoidance behavior in rats. Psychonomic Science, 1971, 23, 213-214.

Boitano, J. J., Lubar, J. F., Auer, J., \& Furnald, M. S. Effects of hippocampectomy on consumatory behavior and movement-inhibition in rats. Physiology \& Behavior, 1968, 3, 901-906.

Clark, C. V. H. Effect of hippocampal and neocortical ablation on scopolamine-induced activity in the rat. Psychopharmacologia, 1970, 17, 289-301.

Cole, S. O., \& Blaszczyk, C. Adaptation to $23 \frac{1 / 2}{2}$ hour food deprivation under CRF conditions: A sex comparison. The Journal of General Psychology, 1971, 58, 131-135.

Coover, G. D., Goldman, L., \& Levine, S. Plasma corticosterone levels during extinction of a lever-press response in hippocampectomized animals. Physiology \& Behavior, 1971, 7,727-732.

Cox, V. E., Kakolew ski, J. W., \& Valenstein, E. S. Ventromedial hypothalamic lesions and changes in body weight and food consumption in male and female rats. Journal of Comparative \& Physiological Psychology, 1969, 67, 320-326.

Critchlow, V., Liebelt, R. A., Bar-Sela, M., Mountcastle, W., \& Lipscomb, H. S. Sex difference in resting pituitary-adrenal function in the rat. American Journal of Physiology, 1963, 205, 807-815.

Denenberg, V. H., \& Morton, J. R. C. Effects of environmental complexity and social groupings upon modification of emotional behavior. Journal of Comparative \& Physiological Psychology, 1962, 55, 1096-1098.

Denti, A., \& Epstein, A. Sex differences in the acquisition of two kinds of avoidance behavior in rats. Physiology \& Behavior, $1972,8,611-615$.

Douglas, $\dot{R}$. J., \& Isaacson, R. L. Hippocampal lesions and activity. Psy chonomic Science, 1964, 1, 187-188.

Endroczi, E., Lissak, K., Bohus, B., \& Kovacs, S. The inhibitory influence of archicortical structures on pituitary-adrenal function. Acta Physiologica Academiae Scientiarum Hungaricae, 1959, 16, 17-22.

Falk, J. L. Theoretical review: The nature and determinants of adjunctive behavior. Physiology \& Behavior, 1971, 6, 577-588.

Fendler, K., Karmos, G., \& Telegdy, G. The effect of hippocampal lesion on pituitary-adrenal function. Acta Physiologica Academiae Scientiarum Hungaricae, 1961, 20, 293-297.

Gotsick, J. E. Factors affecting spontaneous activity in rats with limbic system lesions. Physiology \& Behavior, 1969, 4, $587-593$.

Guth, S., Levine, S., \& Seward, J. P. Appetitive acquisition and extinction effects with exogenous ACTH. Physiology \& Behavior, 1971, 7, 195-200.

Harris, W. C., \& Heistad, G. T. Food-rein torced responding in rats during estrus. Journal of Comparative \& Physiological Psychology, 1970, 70, 206-212.

Isaacson, R. L., Douglas, R. J., \& Moore, R. Y. The effect of radical hippocampal ablation on acquisitson of an avoidance response. Journal of Comparative \& Physiological P.sychology, $1961,54,625-628$.

Isaacson, R. L., \& Wickelgren, W. O. Hippc ampal ablation and passive avoidance. Science, $1962,138,1, \quad+-1106$.

Jarrard, L. E. Hippocampal ablation an operant behavior in rats. Psychonomic Science, 1965, 2, 115-116

Kaplan, J. Approach and inhibitory reactions in rats after bilateral hippocampal damage. Journal of Comparative \& Physiological Psychology, 1968, 65, 274-281.

Kawakami, M., Seto, K., Terasawa, E., Yoshida, K., Miyamoto, $T$ Sekiguchi, $M$ \& Hattori, $Y$ Influence of electrical stimulation and lesion in limbic structure upon biosynthesis of adrenocorticoid in the rabbit. Neuroendocrinology, 1968, 3, 337-348.

Kim, D. Nest building, general activity, and salt preference of rats following hippocampal ablation. Journal of Comparative \& Physiological Psy chology, 1960, 53, 11-16.

Kimble, D. P. The effects of bilateral hippocampal lesions in rats. Journal of Comparative \& Phy siological Psychology, 1963, 56, 272-283.

Kimble, D. P. Hippocampus and internal inhibition. Psychological Bulletin, 1968, 70, 285-295.

Kimble, D. P., \& Coover, G. D. Effects of hippocampal lesions on food and water consumption in rats. Psychonomic Science, $1966,4,91-92$

Kitay, J. I. Sex differences in adrenocortical secretion in the rat. Endocrinology, 1961, 68, 818-824.

Knigge, K. M. Adrenocortical response to stress in rats with lesions in hippocampus and amygdala. Proceedings of the Society for Experimental Biology \& Medicine, 1961, 108, 18-21.

Kondo, C. Y., \& Lorens, S. A. Sex differences in the effects of septal lesions. Physiology \& Behavior, 1971, 6, 481-486.

Kramer, T. J., \& Rilling, M. R. Differential reinforcement of low rates: A selective critique. Psychological Bulletin, 1970, 74, 225-254.

Levine, S. Hormones and conditioning. In W. J. Arnold (Ed.), Nebraska symposium on motivation. Lincoln: University of Nebraska Press, 1968. Pp. 85-101.

Mason, J. W. The central nervous system regulation of ACTH secretion. In H. H. Jasper, L. D. Proctor, R. S. Knighton, W. C. Noshay, and R. T. Costello (Eds.), Reticular formation of the brain. Boston: Little, Brown, 1958. Pp. 645-670.

Murphy, H. M., Wideman, C. H., \& Brown, T. S. A comparison of unilateral and bilateral hippocampal lesions on liver glycogen levels and body weight in the rat. Paper presented at the Society for Neuroscience Third Annual Meeting, San Diego, California, November 1973.

Olton, D. S., \& Isaacson, R. L. Hippocampal lesions and active avoidance. Physiology \& Behavior, 1968, 3, 719-824.

Pagano, R. R., \& Lovely, R. H. Diurnal cycle and ACTH facilitation of shuttlebox avoidance. Physiology \& Behavior, 1972, 8, 721-723.

Ru'ssell, P. A. A note on Lester's theory of exploratory behavior Psychonomic Science, 1971, 25, 161-162.

Schmaltz, L. W., \& Isaacson, R. L. Retention of a DRL-20 schedule by hippocampectomized and partially neodecorticate rats. Journal of Comparative \& Physiological Psychology, 1966, 62, 128-132.

Schmaltz, L. W., \& Isaacson, R. L. The effects of preliminary training conditions upon DRL performance in the hippocampectomized rat. Physiology \& Behavior, 1966, 1, 175-182.

Silber, R. H., Busch, R. D., \& Oslapas, R. Practical procedure for estimation of corticosterone or hydrocortisone. Clinical Chem istry, 1958, 4, 278-285.

Smith, H. V. Effects of environmental enrichment on open-field activity and Hebb-Williams problem solving in rats. Journal of Comparative \& Physiological Psychology, 1972, 80, 163-168.

Snell, G. D. Biology of the laboratory mouse. New York: Dover, 1941.

Steel, R. G. D., \& Torrie, J. H. Principles and procedures in statistics. New York: McGraw-Hill, 1960.

Strong, P. N., \& Jackson, W. J. Effects of hippocampal lesions in rats on three measures of activity. Journal of Comparative \& Physiological Psychology, 1970, 70, 60-65.

Teitelbaum, H., \& Milner, P. Activity changes following partial hippocampal lesions in rats. Journal of Comparative \& Physiological Psychology, 1963, 56, 285-289.

Thorne, B. M., \& Linder, L. H. No change in emotionality of rats following bulbectomy. Psychonomic Science, 1971, 24, 207-208.

Valle, F. P. Effects of strain, sex, and illumination on open field behavior of rats. American Journal of Psychology, 1970, 83, 103-111.

Van Hartesveldt, C. Size of reinforcement and operant responding in hippocampectomized rats. Behavioral Biology, $1973,8,347-356$.

Weiss, J. M., McEwen, B. S., Silva, M. T., \& Kalkut, M. S. Pituitary-adrenal alterations and fear responding. American Journal of Physiology, 1970, 218, 864-868.

Wishart, T., Brohman, L., \& Mogenson, G. Effects of lesions of the hippocampus and septum on hoarding behavior. Animal Behaviour, 1969, 17, 781-784.

(Received for publication February 12, 1974; accepted March 26, 1974.) 